\title{
The time-varying causal relationship between the Bitcoin market and internet attention
}

\author{
Xun Zhang ${ }^{*}$, Fengbin Lu, Rui Tao and Shouyang Wang
}

*Correspondence:

zhangxun@amss.ac.cn

CEFS, MADIS, Academy

of Mathematics and Systems

Science, Chinese Academy

of Sciences, Beijing 100190,

China

\begin{abstract}
The increasing attention on Bitcoin since 2013 prompts the issue of possible evidence for a causal relationship between the Bitcoin market and internet attention. Taking the Google search volume index as the measure of internet attention, time-varying Granger causality between the global Bitcoin market and internet attention is examined. Empirical results show a strong Granger causal relationship between internet attention and trading volume. Moreover, they indicate, beginning in early 2018, an even stronger impact of trading volume on internet attention, which is consistent with the rapid increase in Bitcoin users following the 2017 Bitcoin bubble. Although Bitcoin returns are found to strongly affect internet attention, internet attention only occasionally affects Bitcoin returns. Further investigation reveals that interactions between internet attention and returns can be amplified by extreme changes in prices, and internet attention is more likely to lead to returns during Bitcoin bubbles. These empirical findings shed light on cryptocurrency investor attention theory and imply trading strategy in Bitcoin markets.
\end{abstract}

Keywords: Bitcoin, Internet attention, Google trends, Time-varying granger causality, Multiple bubbles test

JEL Classification: G11, G15, C15

\section{Introduction}

Bitcoin is a decentralized digit currency introduced in 2008 by Satoshi Nakamoto, who has thus far kept their real identity unknown. Recognized as the first established cryptocurrency, Bitcoin, as distinct from traditional currency, has no central bank or single administrator. Bitcoin transactions are verified by network nodes through cryptography and recorded in a publicly distributed ledger called a blockchain. This attracts attention among individuals who lack confidence in the global financial system (Yermack 2015). In the short history of Bitcoin, the 2009-2012 period has been dubbed its early "proof-ofconcept" stage with limited transactions and prices under \$20. Since 2013, Bitcoin has grabbed headlines in the financial news because of its rapid growth and dramatic fluctuations. By the end of November 2013, a unit of Bitcoin was priced at more than $\$ 1,200$, almost 100 times its value at the beginning of that year. In December 2013, the Chinese

(c) The Author(s), 2021. Open Access This article is licensed under a Creative Commons Attribution 4.0 International License, which permits use, sharing, adaptation, distribution and reproduction in any medium or format, as long as you give appropriate credit to the original author(s) and the source, provide a link to the Creative Commons licence, and indicate if changes were made. The images or other third party material in this article are included in the article's Creative Commons licence, unless indicated otherwise in a credit line to the material. If material is not included in the article's Creative Commons licence and your intended use is not permitted by statutory regulation or exceeds the permitted use, you will need to obtain permission directly from the copyright holder. To view a copy of this licence, visit http:// creativecommons.org/licenses/by/4.0/. 
government stepped in with strict regulations to steady the fast development of Bitcoin. ${ }^{1}$ Subsequently, Bitcoin prices fell sharply and remained low until 2015. From 2016, blockchain technology (Garcia et al. 2014; Xu et al. 2019) and massive market manipulations (Griffin and Shams 2018) fostered Bitcoin booms, with Bitcoin reaching its highest price of $\$ 19,783$ on December 17, 2017. Thereafter, Bitcoin prices crashed because of additional regulations and bans implemented by worried governments.

There is extensive academic literature on Bitcoin trading. Several factors influencing Bitcoin prices have been identified, including general factors driving the supply-demand gap (e.g., Buchholz et al. 2012; Kristoufek 2015; Bouoiyour and Selmi 2015; Bouoiyour et al. 2016; Ciaian et al. 2016), and specific factors like investor attractiveness and macrofinance development (Van Wijk 2013). Many studies have claimed that investor attention is a key factor affecting Bitcoin prices (see Kristoufek 2013; Zhang et al. 2018; Eom et al. 2019; Yu et al. 2019; Dastgir et al. 2019). From a theoretical perspective, market attention affects prices in two ways. One is "category learning" where representative investors process more market and sector-wide information than firm-specific information due to limited attention (Peng and Xiong 2006; Peng et al. 2007). This biased constraint of information brings unexplained anomalous market returns. The other is "noise trader" theory. According to Barber and Odean (2008), individual investors are net buyers of attention-grabbing assets; they are likely to make purchase decisions for investment instruments with increasing media coverage. New users are likely to join the transaction network after acquiring related information, which leads to a price increase as the supply is relatively stable in the short term (Garcia et al. 2014).

Bitcoin, as an internet-based digital currency, is, therefore, susceptible to attracting attention from the internet. Bouoiyour et al. (2015), Bouoiyour and Selmi (2015), Nasir et al. (2019), Liu and Tsyvinski (2018), and Zhang and Wang (2020) indicated that Google search data as a proxy of investor attention leads positive Bitcoin returns and is a major driver of price movement. Inspired by this claim, Cretarola and Figà-Talamanca (2019a) proposed an internet attention-based model for Bitcoin price dynamics and derived a closed pricing formula for Bitcoin's European-style derivatives. Meanwhile, the inverse positive Granger causal effect of returns on internet attention was discovered by some literature (Figà-Talamanca and Patacca 2019, 2020).

Although other researchers agreed that internet attention is tightly connected to Bitcoin prices, they argued that the lead-lag relationship changes with time or depends on specific market conditions. Kristoufek (2013) found the effect of increased interest on Bitcoin returns is asymmetric while prices are above or below trend values. Kristoufek (2015) provided supplementary evidence that the co-movement of internet attention and returns is most dominant at high scales and the relationship changes over time. Since 2013, it has been difficult to confidently discern the leader. Ciaian et al. (2016) proposed that the strong impact of internet attention on Bitcoin returns only exists in the early years of Bitcoin trading, then becomes minimal once Bitcoin becomes more established on financial markets. Dastgir et al. (2019) concluded that the bidirectional

\footnotetext{
${ }^{1}$ On December 3, 2013, the central bank of China and four other central government ministries and commissions jointly issued the Notice on Precautions Against the Risks of Bitcoins, defining it as a special "virtual commodity," which is not a currency and should not be circulated and used in the market as a currency.
} 
causal relationship between Bitcoin attention and returns only exists in the poor and superior performance of price returns. In other words, it is only when prices are experiencing extreme changes that increasing investor attention will affect returns. Zhang et al. (2018) stated that Google search volume and Bitcoin returns are anti-persistent cross-correlated; therefore, their cross-correlation decreases over time. Cretarola and Figà-Talamanca (2019b) emphasized that, under suitable conditions, market attention is linked to the formation of a bubble. That is, once a vicious loop between market attention and Bitcoin prices occurs and makes their correlation exceed a threshold value, a price bubble may emerge. Ibikunle et al. (2020) decomposed Bitcoin prices into a noise and an efficient component and demonstrated that investor attention strongly affects the noise component, which represents noise trading, while the efficient component represents informed activity driven by arbitrage.

Another strand of research found no evidence of direct causality between internet attention and Bitcoin returns. Instead, Figà-Talamanca and Patacca $(2019,2020)$, Eom et al. (2019), and Yu et al. (2019) pointed out that internet attention positively affects Bitcoin price volatilities.

A somewhat different conclusion was drawn by Urquhart (2018) and Aalborg et al. (2019). Urquhart documented that internet attention has no significant impact on the returns and the realized volatility of Bitcoin. Conversely, it is the realized volatility that affects next-day attention. Aalborg et al. showed that Google search data only have a weak relationship with daily Bitcoin price volatilities and the relationship is not significant when considering weekly frequency. However, Aalborg et al. agreed that Google search data can help predict the trading volume of Bitcoin.

We argue that the existing literature implies a time-variant relationship between Bitcoin attention and markets. Research that states no causality between Bitcoin attention and price returns takes the data sample as a whole and fails to identify specific periods when the two variables have strong connections. Some market conditions which may affect the causal relationship are specified in literature. Some of these are: whether the price is under or above the trend (Kristoufek 2013), whether returns are in an extreme range (Dastgir et al. 2019), and whether a market bubble emerges or crashes (Ibikunle et al. 2020). Underlying reasons for such a time-variant relationship may be traced to the two positive feedback loops discovered by Garcia et al. (2014): that is, the social cycle between internet attention and price, and the user adoption cycle between internet attention, number of new users, and price. They also observed that spikes in search volume, presumably linked to external events, precede bubble crashes. Similarly, Cretarola and Figà-Talamanca (2019b) concluded that price bubbles are a result of market exuberance (Shiller 2015). The causal relationship is weak when the market is stable. However, the dependence between the two processes would increase and result in a bubble when a vicious loop between market attention and prices is generated.

This paper aims to enhance current research by quantitatively examining the timevarying causal relationship between internet attention and Bitcoin returns, as well as trading volume. We apply the time-varying Granger causality test developed by $\mathrm{Lu}$ et al. (2014) to detect how the relationship changes with time, and further test whether changes in the relationship are connected with extreme market states such as price bubbles. Empirical results present strong time-varying causal effects. Specifically, the level 
of the Granger causal effect of internet attention on price returns depends on changes of price returns and is positively correlated with occurrences of price bubbles. From March 2014 to May 2019, internet attention, measured by the Google search volume index (GSVI), only occasionally led to price returns and was more likely to lead to Bitcoin bubbles. The inverse Granger causal effect of price returns on internet attention is significant during the whole period and became stronger during bubbles, representing time-varying characteristics. These findings are consistent with Kristoufek (2015), Dastgir et al. (2019), Cretarola and Figà-Talamanca (2019b), and Ibikunle et al. (2020), and also suggest a stronger feedback loop between internet attention and price returns with extreme market states, or market exuberance. An additional finding is that a strong bidirectional Granger causal relationship exists between Bitcoin trading volume and internet attention, with stronger causal effects after early 2018. This study also implies that institutional investors can make a profit by attracting attention and manipulating the Bitcoin price. Overall, we argue that Bitcoin presents more risk than traditional financial asserts, and therefore attracts speculators (Zhu et al. 2017).

This study contributes to the literature by quantifying the time-varying causal relationship between Bitcoin attention and price returns, as well as trading volume, which is neglected by the existing literature related to Bitcoin. To the best of our knowledge, this is the first paper to apply the time-varying Granger causality test to explore these relationships. The empirical finding that the time-varying Granger causal effect of internet attention on price returns is only significant during $1 / 5$ of the data sample period is complementary to the findings of Kristoufek (2015), Dastgir et al. (2019), and Cretarola and Figà-Talamanca (2019b). The investigation of periods when internet attention leads Bitcoin returns indicates that the influence of investor attention on price returns increases with the occurrence of bubbles, therefore implying differences in Bitcoin market transition mechanisms during bubbles and relatively stable periods. This empirical finding also provides insight into Bitcoin market trading strategies.

The rest of the paper is organized as follows: "Data" section describes the data; "Methods" section introduces the econometric methodology; "Empirical analysis" section presents the empirical analysis; the discussion of empirical findings is presented in "Discussion" section, and conclusions are provided in "Conclusion" section.

\section{Data}

Bitcoin trading data were acquired from Yahoo Finance. Daily closing prices against the US dollar and trading volume from January 1, 2013 to May 31, 2019 are presented in Fig. 1. Most of the time, trading volume and prices change synchronously. Active Bitcoin trading was initiated on April 28, 2013. However, from 2013 to 2016, trading was relatively limited. The explosive increases of Bitcoin trading that began in 2017 lasted for some time, with Bitcoin prices reaching an all-time peak of $\$ 19,783$ on December 17, 2017. After China's initial ban on Bitcoin trading in September 2017 and its complete ban on February 1, 2018, Bitcoin prices plunged to \$6,914 on February 5, 2018. China's share of global Bitcoin trading volume fell from over 90\% in September 2017 to less than $1 \%$ in June 2018. The total trading volume of Bitcoin fell simultaneously-from a monthly historical high of $\$ 76,344$ million (December 2017) to $\$ 8,582$ million (October 2018). 


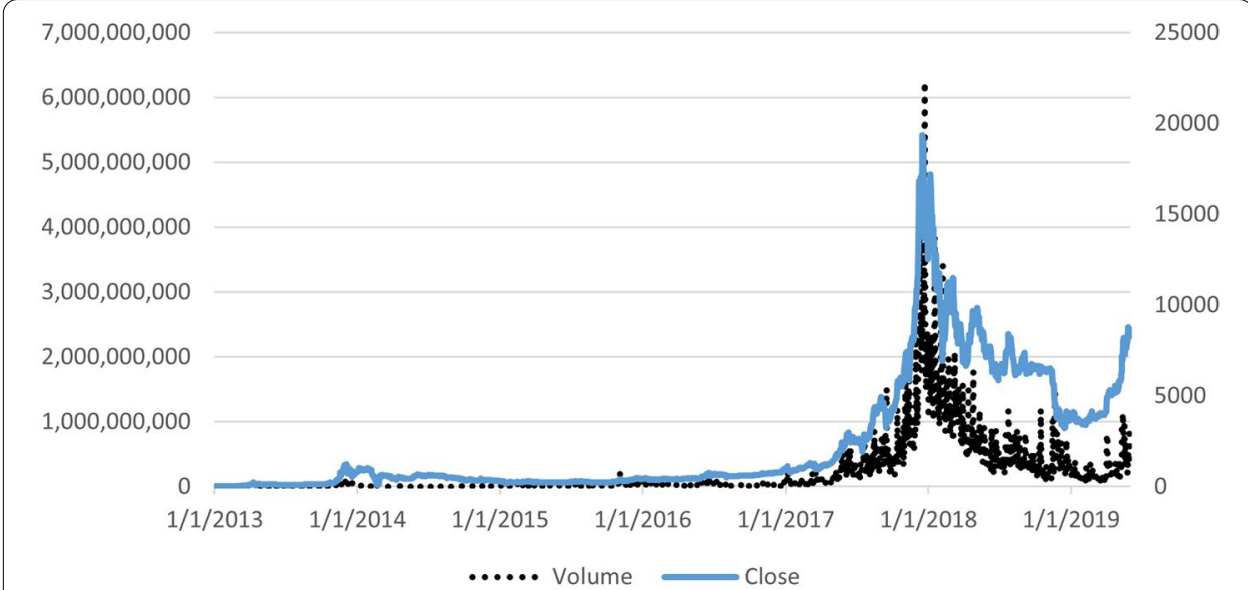

Fig. 1 Daily trading volume (left axis) and closing price of Bitcoin (right axis, in US Dollars)

In our empirical analysis, we focus on Bitcoin returns rather than price levels. Returns are defined as $r_{t}=100 * \ln \left(\mathrm{p}_{\mathrm{t}} / \mathrm{p}_{\mathrm{t}-1}\right)$, where $p_{t}$ denotes the closing price at day $\mathrm{t}$. Similarly, the first difference of logarithm of trading volume is used in empirical analysis, given that logarithm data often have better characteristics of skewness and kurtosis.

The GSVI collected from Google Trends (Google Trends 2019) is used in this study to represent internet attention. Google is the most popular search engine worldwide and its global market share has remained above 88\% since 2013 (Statcounter 2019). GSVI is the relative search volume ratio of a given search term and is normalized to [0,100]. Following literature such as Kristoufek (2013), Philippas et al. (2019), Dastgir et al. (2019), and Urquhart (2018), "Bitcoin" is used as the specific search term. Although Google Trends provides detailed subcategory and location information for search queries, we use GSVI worldwide in all categories to represent the internet attention with the widest possible focus. Google Trends provides multiple frequencies of GSVI-either daily, weekly, or monthly. However, daily data can be downloaded within a maximum window size of 270 days. To get daily GSVI in a longer time range, we separately download daily data values in a smaller time range and link them as a whole time series to broaden the time covered.

The methods we use to transform Google Trends data to a broader time range in daily values are as follows: First, we download monthly GSVI for the entire time frame, which is longer than 270 days. Second, we download daily GSVI for each month residing in the entire time frame. Third, we merge the daily data for each month into a single time series by multiplying their values with the corresponding monthly data and then dividing by 100. As each daily GSVI is normalized in its selected time range, daily GSVI between different months cannot be directly linked. However, the monthly GSVI covering the entire time range can be used as calibration and the linked daily GSVI is comparable between data points.

Figure 2 shows the linked daily GSVI of Bitcoin from January 1, 2013 to May 31, 2019. Da et al. (2011) proposed abnormal GSVI (AGSVI) as another measure for internet attention; we also include it in Fig. 2 and the following analysis. AGSVI is constructed as the logarithm of GSVI at the current time point minus the logarithm of median GSVI during the previous 


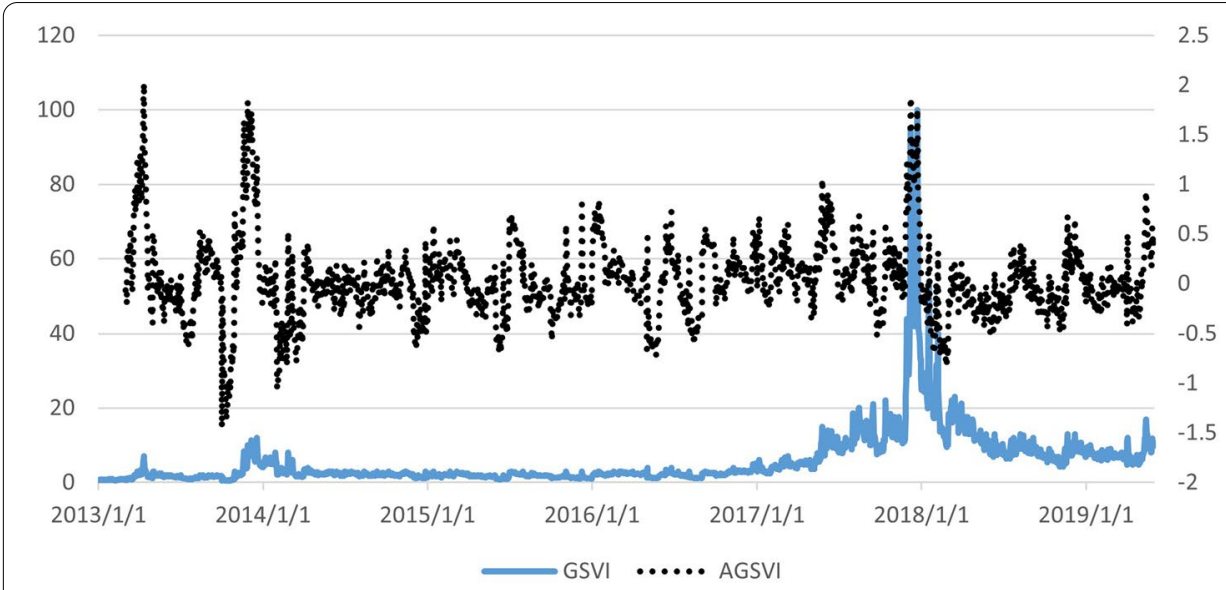

Fig. 2 Daily GSVI (left axis) and AGSVI (right axis) with search term "Bitcoin"

60 days in this paper, while Da et al. (2011) use weekly GSVI, and the median value is taken as GSVI over the past 8 weeks. As the median value over a longer time window captures the normal level of GSVI (Da et al. 2011), AGSVI indicates the extra attention from the internet in a more direct, less unambiguous way. A positive AGSVI value suggests a surge of internet attention. In empirical analysis, we use the first difference of logarithm of GSVI and AGSVI, which is in line with Da et al. and other literature. Figure 2 shows that the changes of GSVI and AGSVI are close, with the highest values appearing when prices peak, and the two time series having more frequent fluctuations after the December 2017 price crash.

\section{Methods}

\section{Time-varying Granger causality test}

The time-varying Granger causality (TV-GC) test proposed by Lu et al. (2014) is applied in this paper to test whether the Granger causal relationship between one time series and another is time-varying or not. Specifically, the unidirectional time-varying Granger causality test statistic from time series $\mathrm{y}_{2, \mathrm{t}}$ to time series $\mathrm{y}_{1, \mathrm{t}}$ is denoted by $\mathrm{Q}_{\mathrm{t}}(\mathrm{k})$ :

$$
\mathrm{Q}_{\mathrm{t}}(\mathrm{k})=\frac{\mathrm{T} \sum_{\mathrm{j}=1}^{\mathrm{T}-1} \mathrm{k}^{2}\left(\frac{\mathrm{j}}{\mathrm{M}}\right) \mathrm{r}_{12, \mathrm{t}}^{2}(\mathrm{j})-\mathrm{C}_{1 \mathrm{~T}}(\mathrm{k})}{\sqrt{2 \mathrm{D}_{1 \mathrm{~T}}(\mathrm{k})}}
$$

where $\mathrm{T}$ is the sample length, $\mathrm{k}(\mathrm{x})$ is the kernel function, and the smoothing parameter is $\mathrm{M}=\mathrm{M}(\mathrm{T}) \rightarrow \infty, \frac{\mathrm{M}}{\mathrm{T}} \rightarrow 0$. Let $\mathrm{e}_{\mathrm{i}, \mathrm{t}}=\mathrm{y}_{\mathrm{i}, \mathrm{t}}-\mathrm{E}\left(\mathrm{y}_{\mathrm{i}, \mathrm{t}} \mid \mathrm{I}_{\mathrm{i}, \mathrm{t}-1}\right)$ be the innovation of $\mathrm{y}_{\mathrm{i}, \mathrm{t}}$ and $\mathrm{I}_{\mathrm{i}, \mathrm{t}}$ be the information set of time series $y_{i, t}$ available at time $t . i=1,2 . r_{12, t}(j)$ is the dynamic conditional correlation of $\mathrm{e}_{1, \mathrm{t}}$ and $\mathrm{e}_{2, \mathrm{t}-\mathrm{j}}$, that is:

$$
\mathrm{r}_{12, \mathrm{t}}(\mathrm{j})=\operatorname{cor}\left(\mathrm{e}_{1, \mathrm{t}}, \mathrm{e}_{2, \mathrm{t}-\mathrm{j}}\right)=\operatorname{cor}\left(\mathrm{y}_{1, \mathrm{t}}-\mathrm{E}\left(\mathrm{y}_{1, \mathrm{t}} \mid \mathrm{I}_{1, \mathrm{t}-1}\right), \mathrm{y}_{2, \mathrm{t}-\mathrm{j}}-\mathrm{E}\left(\mathrm{y}_{2, \mathrm{t}-\mathrm{j}} \mid \mathrm{I}_{2, \mathrm{t}-\mathrm{j}-1}\right)\right)
$$

And $\mathrm{C}_{1 \mathrm{~T}}(\mathrm{k})$ is defined as:

$$
C_{1 T}(k)=\sum_{j=1}^{T-1}\left(1-\frac{j}{T}\right) k^{2}\left(\frac{j}{M}\right), D_{1 T}(k)=\sum_{j=1}^{T-1}\left(1-\frac{j}{T}\right)\left(1-\frac{j+1}{T}\right) k^{4}\left(\frac{j}{M}\right)
$$


Meanwhile, the bidirectional time-varying Granger causality test statistic between $\mathrm{y}_{1}$ and $\mathrm{y}_{2}$ is denoted by $\mathrm{Q}_{\mathrm{b}, \mathrm{t}}(\mathrm{k})$ :

$$
Q_{b, t}(k)=\frac{T \sum_{j=1-T}^{T-1} k^{2}\left(\frac{j}{M}\right) r_{12, t}^{2}(j)-C_{2 T}(k)}{\sqrt{2 D_{2 T}(k)}}
$$

where:

$$
C_{2 T}(k)=\sum_{j=1-T}^{T-1}\left(1-\frac{|j|}{T}\right) k^{2}\left(\frac{j}{M}\right), D_{2 T}(k)=\sum_{j=1-T}^{T-1}\left(1-\frac{|j|}{T}\right)\left(1-\frac{|j|+1}{T}\right) k^{4}\left(\frac{j}{M}\right)
$$

Under the null hypothesis of $\left\{y_{1, t}\right\}$ and $\left\{y_{2, t}\right\}$ are mutually independent, Lu et al. (2004) suggested using $\mathrm{N}(0,1)$ as the asymptotic distributions of the tests $\mathrm{Q}_{\mathrm{t}}$ and $\mathrm{Q}_{\mathrm{b}, \mathrm{t}}$. When $\mathrm{T}, \mathrm{k}(\mathrm{x})$ and $\mathrm{M}$ are given, the stronger the correlation $\mathrm{r}_{12, \mathrm{t}}(\mathrm{j})$, and the larger the time-varying Granger test statistic. Thus, a larger time-varying Granger test statistic indicates a stronger casual effect, which is a useful implication for measuring the time-varying Granger causal effect.

To estimate time-varying Granger tests, we follow the procedure of $\mathrm{Lu}$ et al. (2014). Firstly, the autoregressive moving average (ARMA) model is applied to each time series to remove the effect of autocorrelation and yield the innovations $e_{i, t}=y_{i, t}-E\left(y_{i, t} \mid I_{i, t}-1\right), i=1,2$. Here, $E\left(y_{i, t} \mid I_{i, t-1}\right)$ is the conditional expectation estimated by the popular ARMA model. While there is a strong autoregressive conditional heteroskedasticity (ARCH) effect, the ARMA with generalized autoregressive conditional heteroskedasticity errors (ARMA-GARCH) is applied.

Secondly, the dynamic conditional correlation generalized autoregressive conditional heteroskedasticity (DCC-GARCH) model of Engle (2002) is used to estimate the dynamic conditional correlation $\mathrm{r}_{12, \mathrm{t}}(\mathrm{j})$. Specifically, we suppose that $e_{t}(j)=\left(\begin{array}{c}e_{1, t} \\ e_{2, t-j}\end{array}\right)$ follows Engle's DCC -GARCH model as below:

$$
\begin{aligned}
& \mathrm{e}_{\mathrm{t}}(\mathrm{j}) \mid \mathrm{I}_{\mathrm{t}-1} \sim \mathrm{N}\left(0, \mathrm{D}_{\mathrm{t}, \mathrm{j}} \mathrm{R}_{\mathrm{t}, \mathrm{j}} \mathrm{D}_{\mathrm{t}, \mathrm{j}}\right) \\
& \mathrm{D}_{\mathrm{t}, \mathrm{j}}^{2}=\operatorname{diag}\left\{\omega_{\mathrm{i}, \mathrm{j}}\right\}+\operatorname{diag}\left\{\kappa_{\mathrm{i}, \mathrm{j}}\right\} \circ \mathrm{e}_{\mathrm{t}-1}(\mathrm{j}) \mathrm{e}_{\mathrm{t}-1}^{\prime}(\mathrm{j})+\operatorname{diag}\left\{\lambda_{\mathrm{i}, \mathrm{j}}\right\} \circ \mathrm{D}_{\mathrm{t}-1, \mathrm{j}}^{2} \\
& \quad \mathrm{u}_{\mathrm{t}, \mathrm{j}}=\mathrm{D}_{\mathrm{t}, \mathrm{j}}^{-1} \mathrm{e}_{\mathrm{t}}(\mathrm{j}) \\
& \mathrm{Q}_{\mathrm{t}, \mathrm{j}}=\mathrm{S} \circ\left(\mathrm{u}^{\prime}-\mathrm{A}-\mathrm{B}\right)+\mathrm{Au}_{\mathrm{t}-1, \mathrm{j}} \mathrm{u}_{\mathrm{t}-1, \mathrm{j}}^{\prime}+\mathrm{BQ}_{\mathrm{t}-1} \\
& \mathrm{R}_{\mathrm{t}, \mathrm{j}}=\operatorname{diag}\left\{\mathrm{Q}_{\mathrm{t}, \mathrm{j}}\right\}^{-1} \mathrm{Q}_{\mathrm{t}, \mathrm{j}} \operatorname{diag}\left\{\mathrm{Q}_{\mathrm{t}, \mathrm{j}}\right\}^{-1}
\end{aligned}
$$

The popular maximum likelihood estimation (MLE) is applied for the DCC-GARCH model, and then $r_{12, t}(j)$ is estimated. Similar to Lu et al. (2014), we use the Bartlett kernel function in the test:

$$
\mathrm{k}(\mathrm{x})=\left\{\begin{array}{c}
1-|\mathrm{x}|,|\mathrm{x}|<1 \\
0,|\mathrm{x}| \geq 1
\end{array}\right.
$$

Finally, time-varying Granger test statistics $\mathrm{Q}_{\mathrm{t}}(\mathrm{k})$ and $\mathrm{Q}_{\mathrm{b}, \mathrm{t}}(\mathrm{k})$ are calculated from Eqs. (1) and (3).

The above procedure implies that the estimated correlation $r_{12, t}(j)$ does not suffer from the autocorrelation and the ARCH effect in $y_{i, t}, i=1,2$, for these effects are removed by ARMA and DCC-GARCH models, respectively. 


\section{Multiple bubbles test}

Philips, Shi, and Yu (2015; hereafter, PSY) proposed a practical method for real-time bubble detection. This method is now widely used by central banks and other financial market practitioners for monitoring bubbles as well as crises. It defines bubble expansion as the mildly explosive behavior of asset prices, while during normal market conditions prices typically follow martingale behavior. The null hypothesis describes asset prices under normal market behaviors and is stated as:

$$
y_{t}=g_{T}+y_{t-1}+v_{t}
$$

where $g_{T}=k T^{-\gamma}$ (with constant $\mathrm{k}, \gamma>1 / 2$, and sample size T) describes any mild drift that is of a smaller order than the martingale component and is, therefore, non-dominating (asymptotically negligible). The particular regression model chosen for the PSY procedure is:

$$
\Delta \mathrm{y}_{\mathrm{t}}=\mu+\rho \mathrm{y}_{\mathrm{t}-1}+\sum_{j=1}^{p} \varphi_{j} \Delta \mathrm{y}_{\mathrm{t}-\mathrm{j}}+\varepsilon_{\mathrm{t}},
$$

where $\mathrm{y}_{\mathrm{t}}$ is the asset price at time $\mathrm{t}$, and $\mathrm{p}$ is the lag order determined by information criteria in empirical applications. The error $\varepsilon_{\mathrm{t}}$ follows independent and normal distribution. The null hypothesis and alternative hypothesis are:

$$
H 0: \rho=1 H 1: \rho>1
$$

Under the null hypothesis, $\mathrm{y}_{\mathrm{t}}$ is a unit root process and $\Delta \mathrm{y}_{\mathrm{t}}$ is stationary, while under the alternative hypothesis, $\mathrm{y}_{\mathrm{t} 1}$ is explosive and $\Delta \mathrm{y}_{\mathrm{t}}$ is non-stationary. The hypothesis also implies that right-tailed unit root tests should be used in this setting. Then the PSY method estimates the augmented Dickey-Fuller (ADF), which is the t-ratio of the least squared estimate of $\rho$, based on a recursive evolving algorithm (Phillips et al. 2015). The ADF statistic is calculated recursively from a backward expanding sample sequence, with the endpoint fixed at the observation with interest, and then the sample's starting point changed (limited by minimum window size). The final ADF statistic is selected as the supremum taken over the values of all the ADF statistics in the entire recursion.

However, the performance of this algorithm can be affected by heteroscedasticity and multiplicity and is known to increase the probability of false positives. Phillips and Shi (2018) proposed a new bootstrap procedure, which simultaneously overcomes both heteroscedasticity and multiplicity issues, and we apply it in this paper to detect Bitcoin price bubbles.

\section{Empirical analysis}

\section{Time-varying causality test between internet attention and returns}

Data used in the Granger causality test are the first difference of logarithm of GSVI, AGSVI, and Bitcoin returns, and the first difference of logarithm of trading volume from March 1, 2014 to May 31, 2019. All data are stationary (Table 1). Data before March 2014 are not included for violent swings in market conditions. 
Table 1 Descriptive statistics

\begin{tabular}{lllll}
\hline Variable & dlog_GSVI & AGSVI & Returns & dlog_volume \\
\hline Observations & 1918 & 1918 & 1918 & 1918 \\
Mean & 0.000 & 0.007 & 0.141 & 0.004 \\
Standard deviation & 0.143 & 0.318 & 3.918 & 0.444 \\
Median & -0.012 & -0.009 & 0.179 & -0.031 \\
Minimum & -0.892 & -0.836 & -29.401 & -2.014 \\
Maximum & 1.171 & 1.878 & 24.060 & 1.729 \\
Skewness & 0.766 & 0.855 & -0.256 & 0.301 \\
Kurtosis & 7.593 & 2.854 & 6.641 & 0.912 \\
T statistic of ADF test & $-15.074^{* * *}$ & $-6.563^{* * *}$ & $-11.815^{* * *}$ & $-18.044^{* * *}$ \\
\hline
\end{tabular}

***,**** denote statistical significance at a 1\%,5\%, and 10\% level, respectively. dlog_GSVI represents the first difference of logarithm of the Google search volume index; AGSVI is the abnormal Google search volume index; returns is Bitcoin returns, and dlog_volume is the first difference of logarithm of Bitcoin trading volume

Table 2 Parameters of ARMA-GARCH models

\begin{tabular}{lllll}
\hline Variable & dlog_GSVI & AGSVI & returns & dlog_volume \\
\hline c & -0.001 & 0.007 & $0.130^{*}$ & 0.003 \\
& $(0.002)$ & $(0.031)$ & $(0.070)$ & $(0.002)$ \\
$\operatorname{ar}(1)$ & $0.604^{* * *}$ & $0.911^{* * *}$ & -0.210 & $0.428^{* * *}$ \\
& $(0.048)$ & $(0.012)$ & $(1.862)$ & $(0.032)$ \\
$\operatorname{ma}(1)$ & $-0.792^{* * *}$ & 0.011 & 0.208 & $-0.857^{* * *}$ \\
& $(0.035)$ & $(0.038)$ & $(1.863)$ & $(0.017)$ \\
$\omega$ & $0.009^{* * *}$ & $0.008^{* * *}$ & $0.532^{* * *}$ & $0.082^{* *}$ \\
& $(0.001)$ & $(0.001)$ & $(0.109)$ & $(0.032)$ \\
$a$ & $0.302^{* * *}$ & $0.274^{* * *}$ & $0.123^{* * *}$ & $0.120^{* * *}$ \\
$\beta$ & $(0.041)$ & $(0.038)$ & $(0.017)$ & $(0.031)$ \\
$\beta$ & $0.268^{* * *}$ & $0.328^{* * *}$ & $0.851^{* * *}$ & $0.374^{*}$ \\
AIC & $(0.073)$ & $(0.066)$ & $(0.019)$ & $(0.212)$ \\
& 2394.657 & 2336.657 & $-10,220.110$ & -1899.097
\end{tabular}

***, ${ }^{* *}, *$ denote statistical significance at a $1 \%, 5 \%$, and $10 \%$ level respectively. dlog_GSVI represents the first difference of logarithm of Google search volume index; AGSVI is abnormal Google search volume index; returns is Bitoin returns in logarithm; and dlog_volume is the first difference of logarithm of Bitcoin trading volume. Standard errors are reported in parentheses

The procedure for calculating the time-varying Granger causality (TV-GC) test is: (1) estimating the ARMA-GARCH model for each time series and getting the innovations; (2) estimating the dynamic conditional correlation $\mathrm{r}_{12, \mathrm{t}}(\mathrm{j})$ by the DCC-GARCH model in Eq. (4); (3) calculating TV- GC statistics according to Eqs. (1) and (3).

We conclude that the $\operatorname{ARMA}(1,1)-\operatorname{GARCH}(1,1)$ model is the best ARMA-GARCH model for each time series according to Akaike Information Criterion. Table 2 shows parameters for these ARMA-GARCH models.

Innovations from the above ARMA-GARCH models are modeled as the DCCGARCH process as shown in Table 3. Then, following Lu et al. (2014), M in Eq. (1) is set to 10, and kernel function is set to Bartlett kernel function. A set of DCC-GARCH models of $e_{1, t}$ and $e_{2, t-j}, j=-10,-9, \ldots,-1,1,2, \ldots, 10$, are estimated. Table 3 presents fitted parameters for selected DCC-GARCH models. dcc.alpha and dcc.beta are parameters in the dynamic conditional correlation equation of the DCC-GARCH model, and they are key parameters for identifying whether or not the correlation changes with time. 
Table 3 Parameters of selected DCC-GARCH models

\begin{tabular}{|c|c|c|c|c|}
\hline Variable & $(e G S V I(t), e(t-1))$ & $(e A G S V I(t), e(t-1))$ & $\begin{array}{l}\text { (eGSVI(t), } \\
\text { eVolume }(t-1))\end{array}$ & $\begin{array}{l}\text { (eAGSVI(t), } \\
\text { eVolume }(t-1))\end{array}$ \\
\hline a1 & $\begin{array}{l}0.009^{* * *} \\
(0.001)\end{array}$ & $\begin{array}{l}0.007^{* * *} \\
(0.001)\end{array}$ & $\begin{array}{l}0.009^{* * *} \\
(0.002)\end{array}$ & $\begin{array}{l}0.008^{* * *} \\
(0.002)\end{array}$ \\
\hline a2 & $\begin{array}{l}0.523^{* * *} \\
(0.076)\end{array}$ & $\begin{array}{l}0.990^{* * *} \\
(0.065)\end{array}$ & $\begin{array}{l}0.061^{* * *} \\
(0.076)\end{array}$ & $\begin{array}{l}0.078^{* * *} \\
(0.069)\end{array}$ \\
\hline A11 & $\begin{array}{l}0.319^{* * *} \\
(0.092)\end{array}$ & $\begin{array}{l}0.246^{* * *} \\
(0.090)\end{array}$ & $\begin{array}{l}0.2990^{* * *} \\
(0.097)\end{array}$ & $\begin{array}{l}0.272^{* * *} \\
(0.099)\end{array}$ \\
\hline A22 & $\begin{array}{l}0.132^{* *} \\
(0.207)\end{array}$ & $\begin{array}{l}0.157^{* *} \\
(0.320)\end{array}$ & $\begin{array}{l}0.108^{* * *} \\
(0.021)\end{array}$ & $\begin{array}{l}0.120^{* * *} \\
(0.024)\end{array}$ \\
\hline B11 & $\begin{array}{l}0.260^{* * *} \\
(0.028)\end{array}$ & $\begin{array}{l}0.435^{* * *} \\
(0.034)\end{array}$ & $\begin{array}{l}0.273^{* * *} \\
(0.029)\end{array}$ & $\begin{array}{l}0.328^{* * *} \\
(0.030)\end{array}$ \\
\hline B22 & $\begin{array}{l}0.846^{* * *} \\
(0.031)\end{array}$ & $\begin{array}{l}0.789^{* * * *} \\
(0.045)\end{array}$ & $\begin{array}{l}0.516^{* * *} \\
(0.146)\end{array}$ & $\begin{array}{l}0.404^{* * *} \\
(0.165)\end{array}$ \\
\hline dcc.alpha & $\begin{array}{l}0.027^{* * *} \\
(0.014)\end{array}$ & $\begin{array}{l}0.022^{* * *} \\
(0.015)\end{array}$ & $\begin{array}{l}0.0018^{*} \\
(0.006)\end{array}$ & $\begin{array}{l}0.000 \\
(0.005)\end{array}$ \\
\hline dcc.beta & $\begin{array}{l}0.908^{* * *} \\
(0.055)\end{array}$ & $\begin{array}{l}0.904^{* * *} \\
(0.086)\end{array}$ & $\begin{array}{l}0.980^{* * *} \\
(0.098)\end{array}$ & $\begin{array}{l}0.987^{* * *} \\
(0.393)\end{array}$ \\
\hline
\end{tabular}

***,***, denote statistical significance at a 1\%,5\%, and 10\% level, respectively. e(t), eGSVI $(\mathrm{t}), \mathrm{eAGSVI}(\mathrm{t})$ and eVolume $(\mathrm{t})$ are the innovations of Bitcoin returns, dlog_GSVI, AGSVI and dlog_volume at time $t$, which are estimated from ARMA-GARCH models. (eGSVI(t),e(t - 1)) represents DCC-GARCH model of eGSVI(t) and e(t - 1)

For example, denoting the innovations of dlog_GSVI(t) and $r(t-1)$ as eGSVI $(t)$ and e(t1), in the DCC-GARCH model, dcc.alpha and dcc.beta are all significant at a 5\% level, which means that the dynamic conditional correlation between dlog_GSVI and lagged Bitcoin returns is time-varying. After estimating the DCC-GARCH model, we calculate dynamic conditional correlation $\mathrm{r}_{12, \mathrm{t}}(\mathrm{j})$ according to Eq. (4) and then conduct TV-GC tests by Eq. (1) and (3).

TV-GC test results are presented in Figs. 3, 4, 5. Figure 3 shows TV-GC tests between Bitcoin returns and GSVI, ${ }^{2}$ with Q1 representing the test from Bitcoin returns to GSVI, and Q2 the reverse. Q1 at most time points is significant at a 10\% level, indicating strong Granger causality of Bitcoin returns on GSVI on the whole. Conversely, Q2 is only occasionally significant at a $10 \%$ level, indicating a limited Granger causality of GSVI on Bitcoin returns. However, the changing values of both Q1 and Q2, as well as their changing p-values, indicate that the causal relationships are time-varying. Meanwhile, the smaller values of Q2 than those of Q1 at most time points mean that information spillovers are mainly from Bitcoin returns to GSVI. Figure 4, showing TV-GC tests between Bitcoin returns and AGSVI, indicates similar conclusions for the two variables.

Bidirectional TV-GC tests between Bitcoin returns and internet attention are shown in Fig. 5. Qb1/Qb2 stands for the bidirectional TV-GC test statistics between Bitcoin returns and GSVI/AGSVI, respectively. Both Qb1 and Qb2 are significant at a 10\% level, indicating the existence of strong bidirectional GC. Thus, the instantaneous causal relationship between Bitcoin returns and internet attention is very strong on the whole. A time-varying character can also be found from the bidirectional GC test.

${ }^{2}$ The first difference of logarithm of GSVI (dlog_GSVI) is used in the TV-GC test 

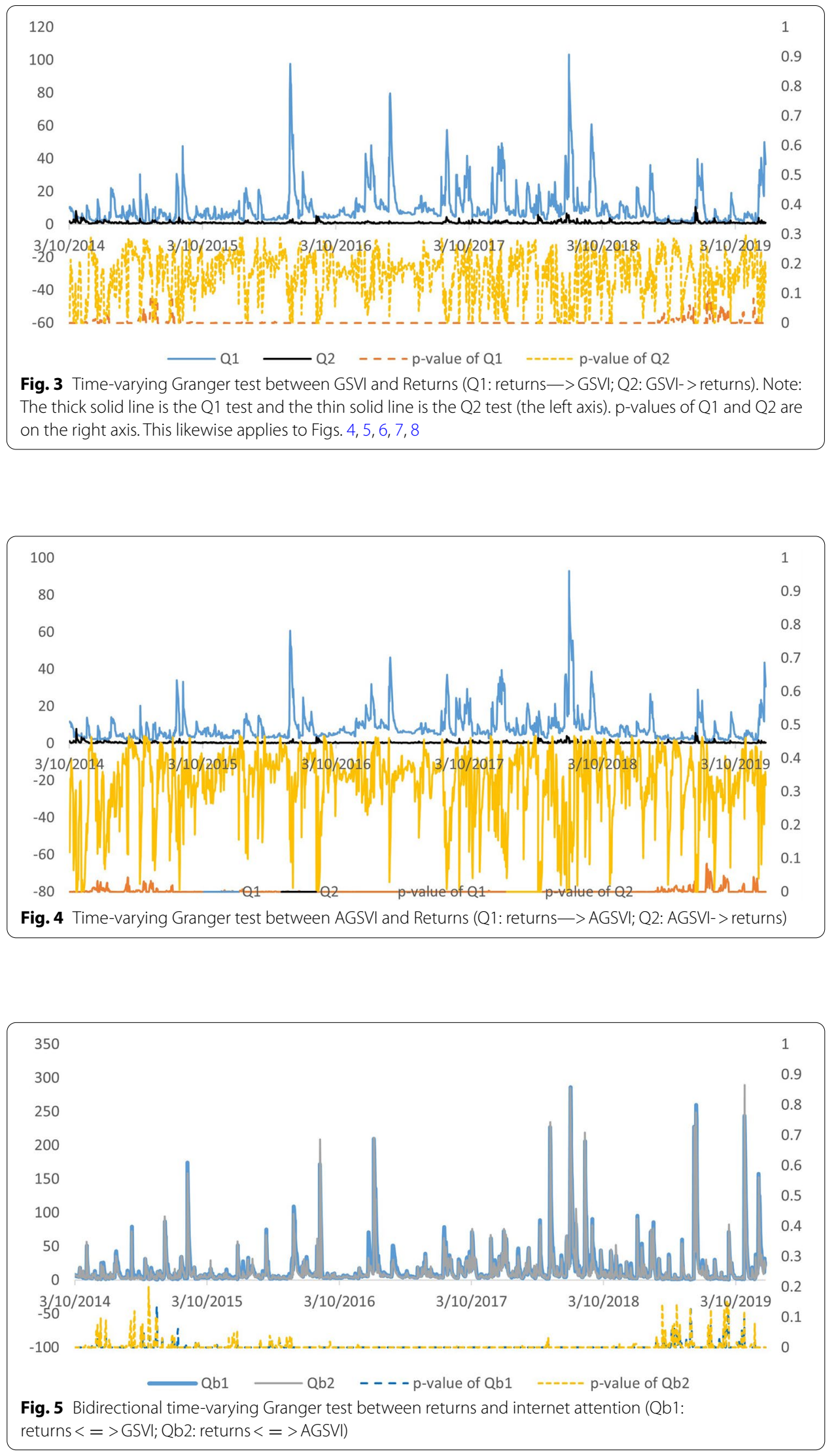


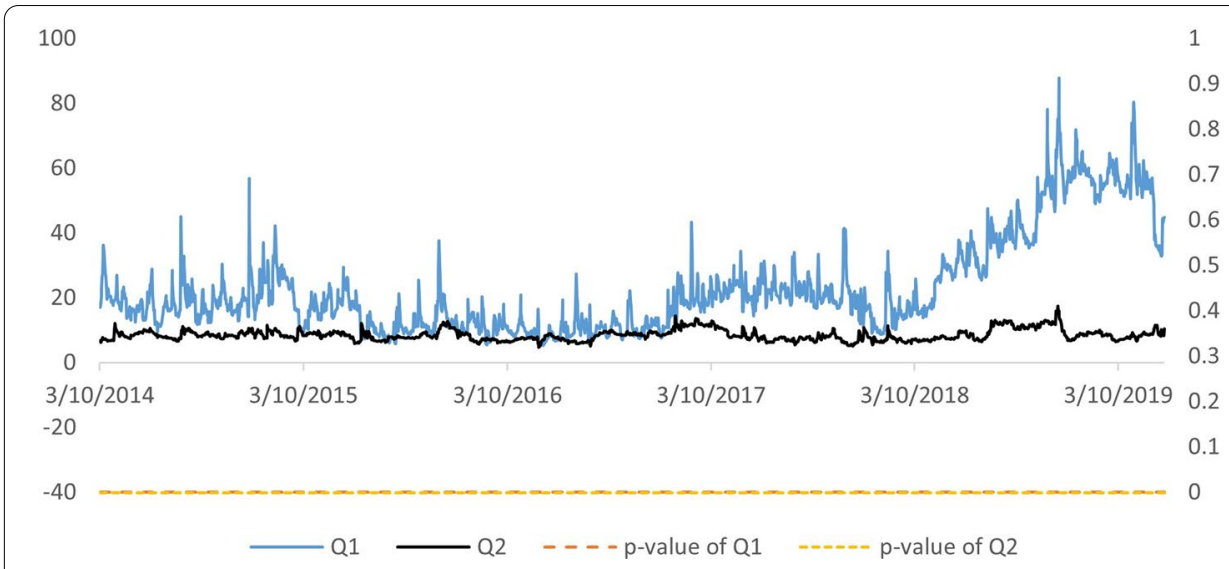

Fig. 6 Time-varying Granger test between GSVI and Trading Volume (Q1: trading volume-> GSVI; Q2: GSVI-> trading volume)

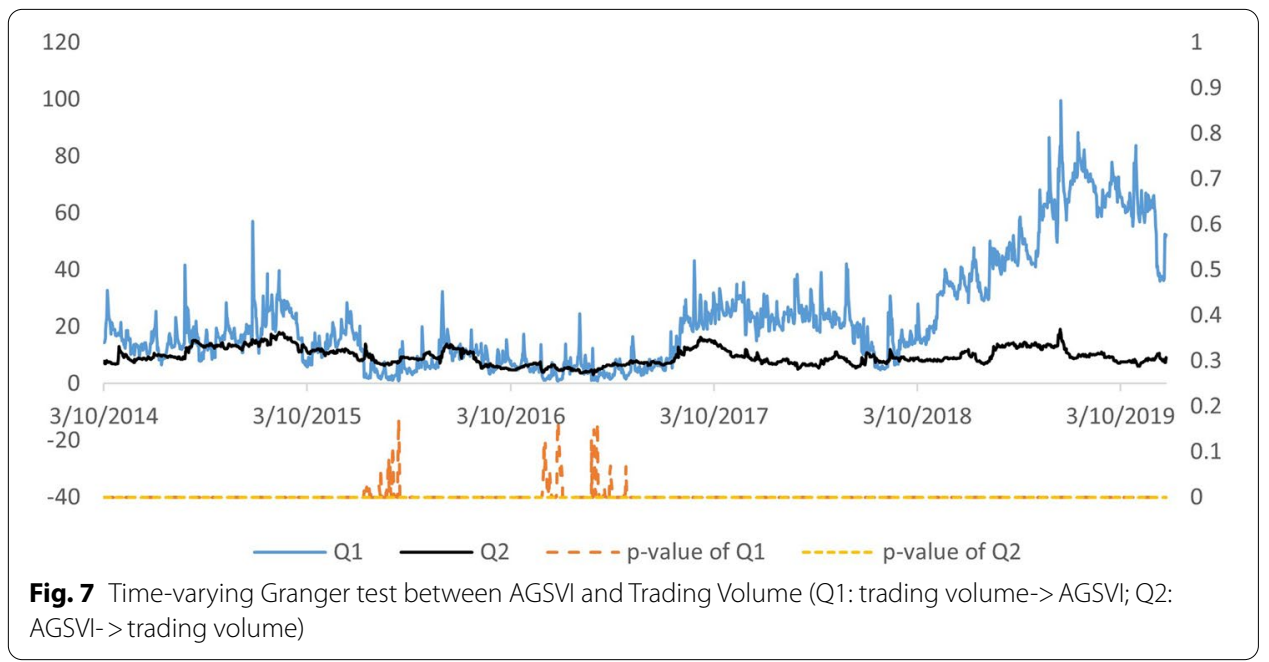

\section{Time-varying causality test between internet attention and trading volume}

The TV-GC tests between internet attention and Bitcoin trading volume are shown in Figs. 6, 7, 8. Figure 6 shows the TV-GC tests between GSVI and trading volume. Q1 is the TV-GC test statistic from trading volume to GSVI, and Q2 is the reverse test. As can be seen from their p-values in Fig. 6, both GC test statistics change with time and are all significant at the $5 \%$ level in the whole sample, which means that there is a very strong unidirectional Granger causality between internet attention and Bitcoin trading volume. With the values of Q2 being often larger than those of Q1, we infer that trading volume has a stronger causal effect on GSVI than the reverse. The values of Q1 present an upward trend from early 2018, which is an interesting finding and indicate the high impact of trading volume on internet attention in recent years.

Figure 7 shows the TV-GC tests between AGSVI and trading volume. Q1 is TV-GC test from trading volume to AGSVI, and Q2 is that from AGSVI to trading volume. We draw similar conclusions in Fig. 7 as in Fig. 6. For example, both Q1 and Q2 are timevarying and significant at a 5\% level. In addition, the Granger causal effect of trading 


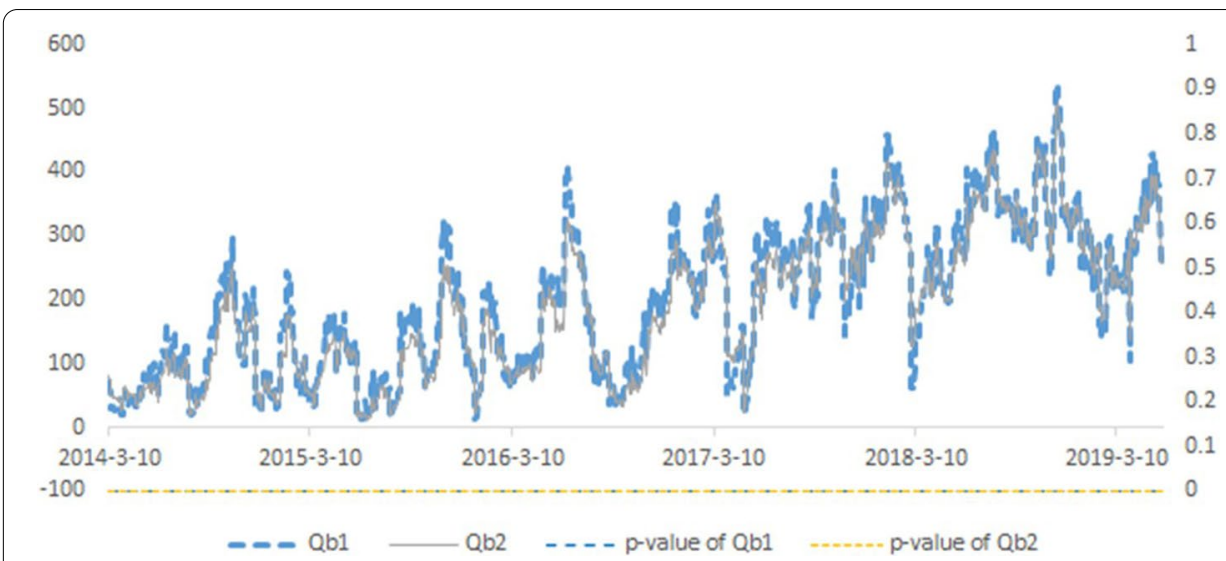

Fig. 8 Bidirectional time-varying Granger test between Trading Volume and internet attention (Qb 1: trading volume $<=>$ GSVI; Qb2: trading volume $<=>$ AGSVI)

volume on AGSVI becomes stronger after early 2018, showing a similar pattern as in Fig. 6. The TV-GC test statistic from trading volume to AGSVI (Q1 in Fig. 7) is often smaller than that from trading volume to GSVI (Q1 in Fig. 6), which means that the latter causal effect is stronger and thus GSVI may be a better candidate for internet attention.

Figure 8 shows bidirectional TV-GC tests between trading volume and internet attention (GSVI and AGSVI). Qb1 is the bidirectional TV-GC test between GSVI and trading volume, and Qb2 is that between AGSVI and trading volume. The upward trend of the two tests indicates an increasing bidirectional causal effect between trading volume and internet attention. The p-values of each test are all lower than 0.01 , which means that bidirectional causality between trading volume and internet attention are all significant at a $1 \%$ level. In addition, each bidirectional TV-GC test is much larger than the corresponding unidirectional one, implying the existence of strong instantaneous Granger causality between trading volume and internet attention.

\section{Bitcoin bubbles and internet attention's effect on Bitcoin returns}

In Sect. 4.1, we find that internet attention only affects Bitcoin returns during occasional time periods. According to Cretarola and Figà-Talamanca (2019a), investor attention may result in a bubble when a vicious cycle between investor attention and prices starts. So it is reasonable to assume that the effect of investor attention on Bitcoin returns is closely related to the emergence of bubbles. To further investigate this phenomenon, we detect bubbles of Bitcoin prices using the PSY method. During the experiment, the multiplicity size control is set to 2 years, and the optimum lag order is selected by Bayesian Information Criterion with a maximum lag order of 6 . The simulation for critical values is repeated 999 times. The PSY test statistics are compared with the $90 \%$ bootstrapped critical values to detect the occurrence of bubbles.

Figure 9 shows the detected bubbles (gray shade) and the test statistics of the TV-GC relationship. The longest bubbles are detected from May 2017 to January 2018. During this period, the Bitcoin price hit its historical high and fluctuated dramatically due to a combination of many complex factors, including expectations of 


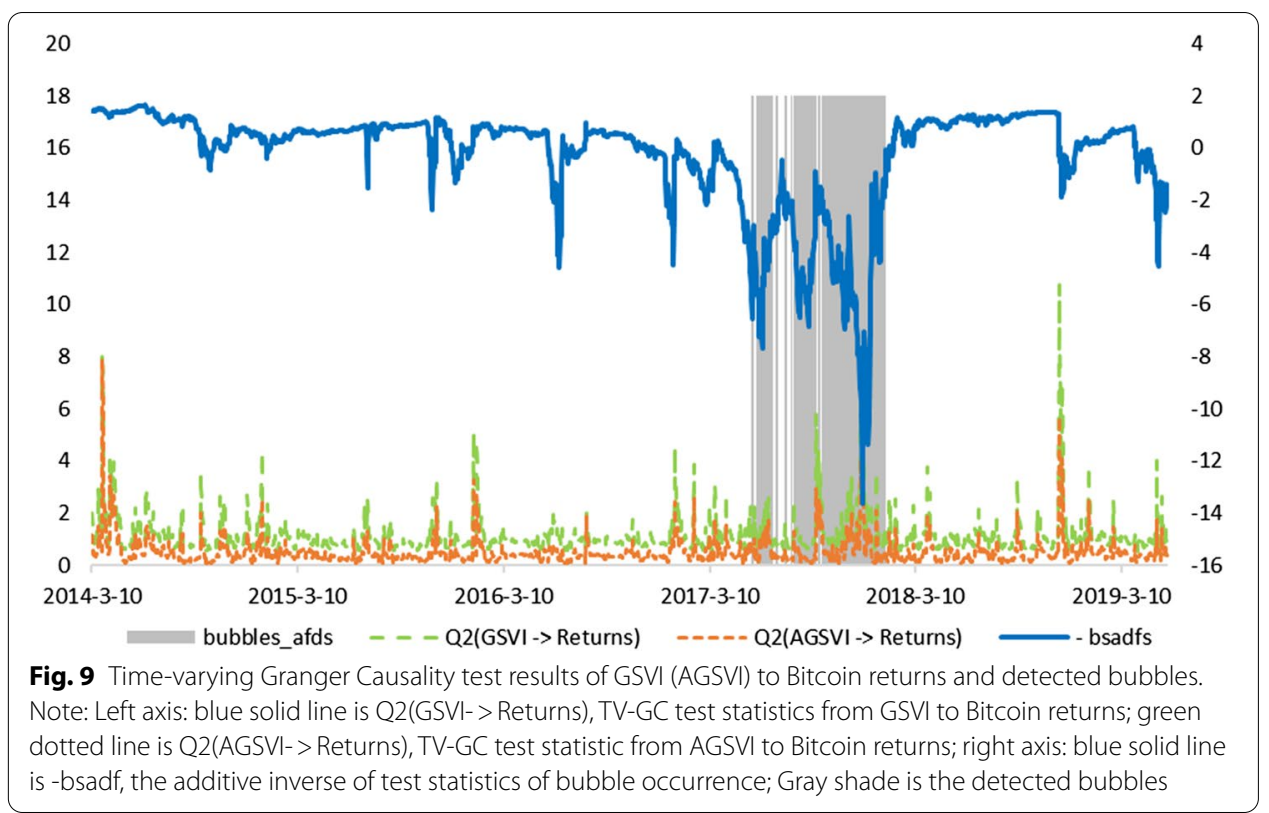

Table 4 Estimated model of TV-GC and bubble test statistics

\begin{tabular}{lll}
\hline Dependent variable & Q2(GSVI-> returns) & Q2 (AGSVI-> returns) \\
\hline C & $1.133^{* * *}$ & $0.505^{* * *}$ \\
BSADF & $(0.017)$ & $(0.012)$ \\
& $0.056^{* * *}$ & $0.030^{* * *}$ \\
F test & $(0.008)$ & $(0.006)$ \\
& $44.739^{* * *}$ & $27.110^{* * *}$ \\
& $(0.000)$ & $(0.000)$ \\
\hline
\end{tabular}

******, denote statistical significance at a 1\%,5\%, and 10\% level, respectively. Q2(GSVI-> returns) and Q2(AGSVI-> returns) are test statistics of unidirectional TV-GC test statistics from GSVI and AGSVI to price returns. BSADF is the bubble test statistic. Significance level of the coefficient test is listed in parenthesis

an interest-rate rise from the US, China's strict regulation, market manipulation, and hacker attack. Detection of this bubble is consistent with Su et al. (2018), Geuder et al. (2019), and Holub and Johnson (2019). Other bubbles lasted for a very short time, such as from mid-June 2016 to early 2017.

In Fig. 9, the blue solid line is the test statistic for multiple bubble detection taken additive inverse. The blue solid line and green dotted line are test statistics of the unidirectional TV-GC test from GSVI and AGSVI to price returns, respectively. It shows that jumps of TV-GC statistics are synchronous with those of bubble test statistics, providing evidence that internet attention is more likely to affect price returns during bubble periods. Regressing TV-GC test statistics on bubble test statistics in Table 4 show the positive coefficients significant at a $1 \%$ level, implying that the two variables are positively related, and that internet attention has a stronger effect on Bitcoin returns during the bubble periods. Although some time periods with large bubble test statistics are not identified as bubbles, a larger TV-GC 
test statistic from internet attention to price returns can be observed during these periods.

\section{Discussion}

The empirical experiments based on daily data from March 1, 2014 to May 31, 2019 show that the Granger causal effect of Bitcoin returns on internet attention is strong during the whole sample period, while the reverse causal effect is weaker and only occasionally significant at a $10 \%$ level. Thus, the unidirectional information spillovers are mainly from Bitcoin returns to internet search data, and not vice versa. This is consistent with findings from Kristoufek (2015), Dastgir et al. (2019), and Cretarola and FigàTalamanca (2019b), which show that internet attention is a key factor in driving Bitcoin prices, but not always a leading indicator of price returns. Unidirectional TV-GC from internet attention to returns is only significant at a $10 \%$ level for about $1 / 5$ of the whole data sample period. Most of these data points with larger TV-GC test statistics reside in time periods with a high probability of price bubbles. Values of both the two unidirectional TV-GC tests change over time, verifying that the causal effect is time-varying. In addition, the two unidirectional causal effects are both likely to increase when the price is close to a bubble level and to decrease when the bubble bursts. In summary, occurrences of price bubbles amplify the interaction between internet attention and Bitcoin returns. Internet attention fails to lead Bitcoin returns when prices are relatively stable but becomes a good leading indicator of price changes during chaotic periods.

Several factors may contribute to time-variations of the relationship. One is the development of Bitcoin trading. Ciaian et al. (2016) found that investor attention has a strong impact on price returns in the early stage of Bitcoin trading, while the impact is minimal after the market is well established. In the early stage, as a new form of payment and the first cyptocurrency, increasing investor attention is more likely to attract new traders and users; thus, it has a stronger impact on prices. Zhang et al. (2018) found that the cross-relation between investor attention and Bitcoin returns decreases over time, which provides supplemental evidence for this trading development theory. However, empirical results cannot provide extra evidence for this theory in this study, because data start from March 2013 and at that time Bitcoin trading was already very active.

The second factor is the noise trader theory. Market attention, aforementioned in Sect. 1, affects price dynamics in two ways, including category learning and noise trading. Internet attention is believed to be a measure of noise traders instead of institution traders according to Da et al. (2011). Ibikunle et al. (2020) also demonstrated that internet attention has a strong effect on noise trading rather than informed trading. When dramatic changes occur in Bitcoin markets, increased media coverage attracts soaring investor attention. These individual investors are net buyers of attention-grabbing assets (Barber and Odean 2008; Hervé et al. 2019). Increasing demand for Bitcoin drives the prices up and a vicious loop between investors' attention and price returns may appear (Cretarola and Figà-Talamanca 2019b). Finally, a bubble is formed. The strong Granger causality between investor attention and price returns continues until the bubble bursts. Ciaian et al. (2016) and Kristoufek (2015) provided more details about the feedback effect between Bitcoin and online attention. 
However, bidirectional Granger causality between returns and internet attention is very strong on the whole. The corresponding test statistics are also much larger than the unidirectional ones, implying there is a very strong intraday (or instantaneous) interaction between price returns and internet attention. As a reference, Kristoufek (2015) also discovered that the co-movement of internet attention and Bitcoin returns is most dominant at high scales.

Time-varying causality tests between internet attention and trading volume show that each variable significantly leads another and the causal effects vary obviously with time. This confirms that trading volume can be taken as an efficient measure of investor attention. We also find an even stronger impact of Bitcoin trading volume on internet attention starting from early 2018. This is likely to be the result of the rapid increase in Bitcoin investors starting from December 2017, when Bitcoin value reached its alltime high. Taking Coinbase, the largest cryptocurrency trading platform, for example, its monthly usage reached 11.1 million in January 2018, almost 28 times the number in January 2017 and 2.5 times the number in December 2017. In 2019, the number of users on Coinbase passed 30 million with 8 million having joined the exchange during 2018 . It is believed that a large portion of these newly registered users is individual traders, thereby increasing the interaction between trading volume and online search volume. In addition, we find that GSVI is a better candidate for internet attention compared with AGSVI. Granger causality effects of GSVI on both Bitcoin returns and trading volume are stronger than those of AGSVI. To complement the TV-GC test, the traditional static Granger causality test between Bitcoin returns and trading volume is examined. The static Granger causality test results show that Granger causality from Bitcoin returns to trading volume is significant at a $1 \%$ level, while the reverse causality is not significant at a 5\% level. This means that information spillovers in Bitcoin markets are mainly from Bitcoin returns to trading volume but not vice versa, which is similar to the conclusions on Granger causality between Bitcoin returns and internet attention.

\section{Conclusion}

In exploring the time-varying relationship between Bitcoin markets and internet attention as measured by GSVI, we find that the Granger causal relationship between Bitcoin returns and internet attention apparently changes with time. There is a strong Granger causal relationship between the trading volume of Bitcoin and internet attention, with a stronger impact of Bitcoin trading volume on internet attention since January 2018. Returns of Bitcoin prices strongly lead to changes in internet attention, while internet attention only occasionally affects Bitcoin returns. In particular, internet attention is likely to affect returns of Bitcoin prices in a bubble, which implies that the emergence of bubbles may accelerate the impact of internet attention on Bitcoin prices.

The results are valuable to the understanding of the transition channel of cryptocurrency. Given that it is a new cryptocurrency, Bitcoin is more likely to be a risky investment that attracts speculative traders. When the Bitcoin price surges, especially when the bubble emerges, more speculators are attracted to the Bitcoin market. This leads to increasing market attention and trading volume, triggering a higher market price and potentially a bubble. Our findings are consistent with Dastgir et al. (2019), who show 
that extreme price changes increase the attention of investors. However, we show that the Granger causal effects in the Bitcoin market are time-varying and the process is more complex than initially thought. Furthermore, the stronger Granger causal effect of market attention on Bitcoin returns during the occurrence of price bubbles indicates that traders may transiently make a profit by boosting a bubble. That is, institutional investors purposely increase Bitcoin's media coverage and increase its search frequency, thus attracting more individual traders, and making a profit by manipulating the Bitcoin price. In fact, this trading strategy may have been used by informed investors in Bitcoin markets. According to Feng et al. (2018), informed traders can make large profits by building their positions 2 days before large positive events and 1 day before large negative events. For individual investors, it is important to be cautious of sudden Bitcoin media coverage and to be able to foresee any resulting price bubble.

Future work utilize information from a broader set of social media sources. This paper uses only Google search data to represent internet attention on Bitcoin. However, other social media, such as Wikipedia, Twitter, and Facebook, provide valuable information for predicting Bitcoin markets (Feng et al. 2018). Posts from trading platforms, such as Coinbase, Binance, and Huobi are also directly related to Bitcoin traders' attention and sentiment. Specifically, the more that hedge funds and companies show interest and invest in cryptocurrency, the more worthwhile it is to identify how retail investor attention and institutional attention impact the markets, respectively.

\footnotetext{
Abbreviations

TV-GC:Time-varying Granger causality; GSVI: Google search volume index; AGSVI: Abnormal Google search volume index; ARMA model: Autoregressive moving average model; DCC-MGARCH model: Dynamic conditional correlation multivariate generalized autoregressive conditional heteroskedasticity model; PSY: Philips, Shi and Yu (Phillips et al. 2015); AIC: Akaike Information Criterion; BIC: Bayesian Information Criterion.
}

\section{Acknowledgements}

We sincerely thank Editor, Gang Kou, and the five reviewers for their very insightful comments, which helped improve the quality of this paper very much.

\section{Authors' contributions}

XZ designed this work, acquired and analyzed the data, and was a major contributor in writing the manuscript. FL interpreted the results of time-varying Granger Causality test and contributed to writing the manuscript. RT wrote the code of time-varying Granger Causality test and was responsible for running all the codes in this paper. SW had major contribution to the conception of this work, drafted the work and substantively revised it. All authors read and approved the final manuscript.

\section{Authors' information}

Xun Zhang is currently an associate professor at Academy of Mathematics and Systems Science, Chinese Academy of Sciences (AMSS, CAS). Her research interests cover a broad set of topics in the art of empirical macroeconomics,energy economics and energy finance. She has more than 10 years of academic experiences.

Fengbin Lu is an assitant researcher at AMSS, CAS. His researches focus on time varying econometric models and forecasting.

Rui Tao is a Ph.D. student in AMSS, CAS.

Shouyang Wang is a Bairen Distinguished Professor of management science with AMSS, CAS, and a Changjiang Chair Professor of management science and engineering with the University of Chinese Academy of Sciences, Beijing. His current research interests include decision analysis, risk management, economic analysis, and forecasting.

Funding

The paper received financial support from the National Natural Science Foundation of China (Nos. 71422015, 71871213) and the National Center for Mathematics and Interdisciplinary Sciences, Chinese Academy of Sciences.

Availability of data and materials

The datasets used during the current study are available from the corresponding author on reasonable request. 


\section{Declarations}

Competing interests

The authors declare that they have no competing interests.

Received: 10 October 2019 Accepted: 7 August 2021

Published online: 01 September 2021

\section{References}

Aalborg HA, Molnár P, de Vries JE (2019) What can explain the price, volatility and trading volume of Bitcoin? Financ Res Lett 29:255-265

Barber BM, Odean T (2008) All that glitters: the effect of attention and news on the buying behavior of individual and institutional investors. Rev Financ Stud 21(2):785-818

Bouoiyour J, Selmi R (2015) What does Bitcoin look like? Ann Econ Financ 16(2):449-492

Bouoiyour J, Selmi R, Tiwari A (2015) Is Bitcoin business income or speculative bubble? Unconditional vs. conditional frequency domain analysis. Ann Financ Econ 10(1):1-23

Bouoiyour J, Selmi R, Tiwari AK, Olayeni OR (2016) What drives Bitcoin price. Econ Bull 36(2):843-850

Buchholz M, Delaney J, Warren J, Parker J (2012) Bits and bets, information, price volatility, and demand for Bitcoin. Economics 312:2-48

Ciaian P, Rajcaniova M, Kancs D (2016) The economics of BitCoin price formation. Appl Econ 48(19):1799-1815

Cretarola A, Figà-Talamanca G (2019a) Bubble regime identification in an attention-based model for Bitcoin and Ethereum price dynamics. Econ Lett. https://doi.org/10.1016/j.econlet.2019.108831

Cretarola A, Figà-Talamanca G (2019b) Detecting bubbles in Bitcoin price dynamics via market exuberance. Ann Oper Res. https://doi.org/10.1007/s10479-019-03321-z

Cretarola A, Figà-Talamanca G, Patacca M (2019) Market attention and Bitcoin price modeling: theory, estimation and option pricing. Decisions Econ Finan. https://doi.org/10.1007/s10203-019-00262-x

Da Z, Engelberg J, Gao P (2011) In search of attention. J Finance 66(5):1461-1499

Dastgir S, Demir E, Downing G, Gozgor G, Keung C, Lau M (2019) The causal relationship between Bitcoin attention and Bitcoin returns: evidence from the Copula-based Granger causality test. Financ Res Lett 28:160-164

Engle R (2002) Dynamic conditional correlation. J Bus Econ Stat 20(3):339-350

Eom C, Kaizoji T, Kang SH, Pichl L (2019) Bitcoin and investor sentiment: statistical characteristics and predictability. Phys A 514:511-521

Feng W, Wang Y, Zhang Z (2018) Informed trading in the Bitcoin market. Finance Res Lett 26(11):63-70

Figá-Talamanca G, Patacca M (2019) Does market attention affect Bitcoin returns and volatility? Decisions Econ Finan 42(1):135-155

Figà-Talamanca G, Patacca M (2020) Disentangling the relationship between Bitcoin and market attention measures. $J$ Ind Bus Econ 47(1):71-91

Garcia D, Tessone CJ, Mavrodiev P, Perony N, Garcia D (2014) The digital traces of bubbles: feedback cycles between socio-economic signals in the Bitcoin economy. J R Soc Interface 11(99):20140623

Geuder J, Kinateder H, Wagner NF (2019) Cryptocurrencies as financial bubbles: the case of Bitcoin. Financ Res Lett. https://doi.org/10.1016/j.frl.2018.11.011

Google Trends (2019). https://trends.google.com. Accessed on 22 July 2019

Griffin JM, Shams A (2018) Is Bitcoin really un-tethered? SSRN: https://ssrn.com/abstract=3195066 or http://dx.doi. org/10.2139/ssrn.3195066

Hervé F, Zouaoui M, Belvaux B (2019) Noise traders and smart money: evidence from online searches. Econ Model $83: 141-149$

Holub M, Johnson J (2019) The impact of the Bitcoin bubble of 2017 on Bitcoin's P2P market. Financ Res Lett 29:357-362

Hong Y (1996) Testing for independence between two covariance stationary time series. Biometrika 83(3):615-625

Ibikunle G, McGroarty F, Rzayev K (2020) More heat than light: Investor attention and bitcoin price discovery. Int Rev Financ Anal 69(October 2019):101459

Kristoufek L (2013) BitCoin meets google trends and wikipedia: quantifying the relationship between phenomena of the Internet era. Sci Rep 3:3415

Kristoufek $L$ (2015) What are the main drivers of the Bitcoin price? Evidence from wavelet coherence analysis. PLoS ONE 10(4):e0123923

Liu Y, Tsyvinski A (2018) Risks and returns of cryptocurrency (No. w24877). National Bureau of Economic Research. https:// doi.org/10.2139/ssrn.3226952

Lu F, Hong Y, Wang S, Lai K, Liu J (2014) Time-varying Granger causality tests for applications in global crude oil markets. Energy Economics 42:289-298

Nasir MA, Huynh TLD, Nguyen SP, Duong D (2019) Forecasting cryptocurrency returns and volume using search engines. Financ Innov. https://doi.org/10.1186/s40854-018-0119-8

Peng L, Xiong W (2006) Investor attention, overconfidence and category learning. J Financ Econ 80(3):563-602

Peng L, Xiong W, Bollerslev T (2007) Investor attention and time-varying comovements. Eur Financ Manag 13(3):394-422. https://doi.org/10.1111/j.1468-036X.2007.00366.x

Philippas D, Rjiba H, Guesmi K, Goutte S (2019) Media attention and Bitcoin prices. Financ Res Lett 30:37-43

Phillips P, Shi S (2018) Real time monitoring of asset markets: bubbles and crises. Cowles Foundation Discussion Paper No. 2152. SSRN: https://ssrn.com/abstract=3299498 or https://doi.org/10.2139/ssrn.3299498. 
Phillips P, Shi S, Yu J (2015) Testing for multiple bubbles: historical episodes of exuberance and collapse in the S\&P 500. Int Econ Rev 56(4):1043-78.

Shiller RJ (2015) Irrational exuberance: revised and expanded, 3rd edn. Princeton University Press, Princeton

Statcounter (2019) https://gs.statcounter.com. Accessed on 22 July 2019

Su CW, Li ZZ, Tao R, Si DK (2018) Testing for multiple bubbles in Bitcoin markets: a generalized sup ADF test. Jpn World Econ 46:56-63

Urquhart A (2018) What causes the attention of Bitcoin ? Econ Lett 166:40-44

Xu M, Chen X, Kou G (2019) A systematic review of blockchain. Financ Innov. https://doi.org/10.1186/s40854-019-0147-z Yermack D (2015) Is Bitcoin a real currency? An economic appraisal. In: Handbook of digital currency. Academic Press, pp $31-43$

Yu JH, Kang J, Park S (2019) Information availability and return volatility in the Bitcoin Market: analyzing differences of user opinion and interest. Inf Process Manag 56(3):721-732

Van Wijk D (2013) What can be expected from the Bitcoin? Erasmus Universiteit Rotterdam. Working paper no. 345986

Zhang W, Wang P, Li X, Shen D (2018) Quantifying the cross-correlations between online searches and Bitcoin market. Phys A 509(92):657-672. https://doi.org/10.1016/j.physa.2018.06.073

Zhang W, Wang P (2020) Investor attention and the pricing of cryptocurrency market. Evol Inst Econ Rev 17(2):445-468 https://doi.org/10.1007/s40844-020-00182-1

Zhu Y, Dickinson D, Li J (2017) Analysis on the influence factors of Bitcoin's price based on VEC model. Financ Innov. https://doi.org/10.1186/s40854-017-0054-0

\section{Publisher's Note}

Springer Nature remains neutral with regard to jurisdictional claims in published maps and institutional affiliations.

\section{Submit your manuscript to a SpringerOpen ${ }^{\circ}$ journal and benefit from:}

- Convenient online submission

- Rigorous peer review

Open access: articles freely available online

- High visibility within the field

Retaining the copyright to your article

Submit your next manuscript at $>$ springeropen.com 